\title{
CONTROL, CONTINGENCIA Y PARANOIA EN EL CUERPO JUVENIL A TRAVÉS DEL USO DEL CELULAR EN LIMA'
}

\author{
Jerjes LOAYZA JAVIER \\ Universidad Ricardo Palma \\ manuel.loayza@urp.edu.pe
}

\begin{abstract}
RESUMEN
La investigación busca comprender el modo en que el celular lleva a sus usuarios a resignificar sus vidas a través del uso del celular en jóvenes que oscilan entre los 15 y 22 años de la ciudad de Lima. Se plantea la etnografía virtual, la historia de vida y la autobiografía como técnicas metodológicas. Se vislumbra el ejercicio de un control a través del celular, tanto a nivel de las parejas, como ante la necesidad de manipularlo y ejercerlo como parte de uno mismo. Esta organicidad, que incorpora a la máquina como parte del cuerpo juvenil al punto de incrementar el nivel de contingencia en el fluir cotidiano.
\end{abstract}

\section{PALABRAS CLAVE}

Cuerpo juvenil, control, ensamblaje, contigencia.

\section{CONTROL, CONTINGENCY AND PARANOIA IN THE JUVENILE BODY THROUGH THE USE OF CELL PHONES IN LIMA}

\begin{abstract}
The research seeks to understand the way in which the cell phone leads its users to re meaning their lives through the use of the cell phone in young people ranging from 15 to 22 years of the city of Lima. Virtual ethnography, life history and autobiography are proposed as methodological techniques. You can see the exercise of a control through the cell phone, both at the level of couples, and before the need to manipulate it and exercise it as part of oneself. This organicity, which incorporates the machine as part of the youth body to the point of increasing the level of contingency in the daily flow.
\end{abstract}

\section{KEYWORDS}

Youth body, control, assembly, contingency.

Recibido: $16 / 5 / 2017$

Aprobado: $30 / 11 / 2017$

Investigación realizada con el auspicio de la Universidad Ricardo Palma. 


\section{Introducción}

a investigación tiene como principal objetivo comprender el modo en que el celular lleva a sus usuarios a re significar sus vidas a través del uso del celular y sus diversas aplicaciones en jóvenes que oscilan entre los 15 y 22 años de la ciudad de Lima. Para ello se plantea la etnografía virtual, la historia de vida y la autobiografía como técnicas para recolectar información del mundo de la vida cotidiana de sus actores.

Las nuevas tecnologías van sumándose al cotidiano fluir de la sociedad y en especial de los nativos digitales quienes han sabido sumarse a la celebración de la cibercultura mediante el consumo constante de sus dispositivos. Su poderosa intermediación en la interacción nos lleva a la necesidad de pensar en su impacto que tendría en las diferentes dimensiones sociales estructurantes de las juventudes en Lima.

\section{Metodología}

Para la realización de la investigación se emplearon tres técnicas: la etnografía virtual, la autobiografía y la historia de vida. A continuación se detallan:

Etnografía virtual: Permitió captar el punto de vista del otro juvenil en su posición ante la vida, comprendiendo su visión del mundo. Para Hine (2004) la etnografía virtual en lugar de ser inherentemente sensible, adquiriría sensibilidad en su uso, interpretación y reinterpretación. Sautu, Boniolo, Dalle y Elbert (2005) postularían cómo es que el propio investigador se incluye a la realidad intersubjetiva, en tanto actor social interviniente, contribuyendo a producir y reproducir el contexto de interacción que desea investigar. Esta investigación etnográfica se centra en los flujos y las conexiones en vez de las localidades y los limites como principios organizadores (Hine, 2004).

Autobiografía: los entrevistados realizaron un diario extenso del uso de su celular a lo largo de una semana, detallando cada instante. Recuérdese que toda representación del individuo es necesariamente una representación del vínculo social que le es consustancial (Augé, 1998: 26).

Historias de vida: Siguiendo la dinámica anterior los participantes decidieron relatar cómo es que su pasado es caracterizado por la utilización de los celulares. Aunque no se limitaron de ningún modo a preguntas predefinidas, las referencias que sirvieron de guías para dinamizar el diálogo fueron:

- ¿Qué recuerdas de cada celular que has tenido?

- Recuerda los buenos momentos y los malos, cada pequeña anécdota.

- Realiza un recuento de todos los celulares tomándote tu tiempo.

- Recuerda cómo los obtuviste, por qué cambiabas de cada celular.

Cabe destacar que las entrevistas tuvieron lugar en el año 2013. A continuación se presentan sus características más relevantes: 


\begin{tabular}{|l|l|l|l|l|l|}
\hline Nombre & Sexo & Edad & Actividad a la que se dedica & Distrito & Zona de Lima \\
\hline Angélica & F & 22 & Estudia en una universidad privada. & Surco & Sur \\
\hline Dina & F & 19 & Estudia en una universidad privada. & Ate & Este \\
\hline Katherine & F & 18 & $\begin{array}{l}\text { Estudia Ingeniería Civil en una } \\
\text { universidad privada. }\end{array}$ & Villa El Salvador & Sur \\
\hline Cinthya & F & 18 & $\begin{array}{l}\text { Estudia Traducción en una universi- } \\
\text { dad privada. }\end{array}$ & Surco & Sur \\
\hline Sara & F & 22 & $\begin{array}{l}\text { Estudia Sociología en una universi- } \\
\text { dad nacional y trabaja como recep- } \\
\text { cionista. }\end{array}$ & $\begin{array}{l}\text { San Juan de } \\
\text { Lurigancho }\end{array}$ & Este \\
\hline Valerio & M & 20 & Estudia en una universidad privada. & Santa Anita & Este \\
\hline Ernesto & M & 18 & Estudia en una universidad privada. & Chorrillos & Sur \\
\hline Carl & M & 19 & $\begin{array}{l}\text { Estudia Traducción en una universi- } \\
\text { dad privada. }\end{array}$ & $\begin{array}{l}\text { San Juan de } \\
\text { Miraflores }\end{array}$ & Sur \\
\hline Santos & M & 20 & $\begin{array}{l}\text { Estudia Arquitectura en una universi- } \\
\text { dad privada. }\end{array}$ & Surco & Sur \\
\hline Elvis & M & 22 & Estudia en una universidad privada. & San Isidro & Centro \\
\hline Pablo & M & 15 & Estudia en la educación secundaria. & $\begin{array}{l}\text { Villa María del } \\
\text { Triunfo }\end{array}$ & Sur \\
\hline
\end{tabular}

La muestra elegida es por conveniencia, dado que se tuvo acceso a un grupo de participantes que provenían de espacios de esparcimiento lúdico como discotecas, así como estudiantes de una universidad privada en donde el investigador era docente. En general, parte del mundo de la vida cotidiana del autor. Se establece su participación reflexiva como punto primordial para profundizar el debate en torno al uso del celular.

\section{Inquietudes y divergencias frente al celular}

Se creía que el chat sería un simple complemento en los celulares sin centralidad alguna ya que las computadoras eran los soportes favoritos para el uso de las redes sociales. Sin embargo la fácil movilidad de los celulares independiza a los usuarios, tal como sostiene un usuario: Horas después estando en la laptop de igual manera el celular siempre lo traigo, pongo al costado y a cada rato reviso ya sea para ver la hora, si hay algún mensaje o llamada como mayormente lo tengo en vibrador ${ }^{2}$. La complementariedad entre cuerpo humano y celular no humano no pierde su valía ni por el uso de la computadora: los mediadores no se estorban, menos aún aquel que, ya sea en el bolsillo, la cartera o en lo íntimo de los cuerpos femeninos -en los pechos o en las caderas por ejemplo- siempre está al alcance.

Dina comenta en una autobiografía hecha por ella misma: Estando ya en casa para la hora del almuerzo siempre traigo conmigo el celular, ya sea en mi bolsillo o lo pongo sobre la mesa, mayormente sobre la mesa; y fijando o revisando el celular de manera espontánea,

2 Diario de campo. Abril 2013. 
por momentos no puedo evitar de hacerlo ${ }^{3}$. Esta omnipresencia nos lleva a hablar, una vez más, de una concatenación de significados en que los objetos valen como uno o nada, sin importar lo complicados que pueden ser internamente (Latour, 2008: 117). En el caso de Elvis el uso del celular le permite prescindir de la computadora: en sí la uso más para mis trabajos, porque no suelo entrar mucho a la computadora, porque estoy por todos lados 4 .

Inclusive el contexto educativo es un espacio en donde se busca el modo en que tanto estudiante como celular se unen para contrarrestar el aburrmiento. Una complicidad que no deja de sorprender a otros estudiantes: hay siempre quienes tienen la adicción de estar allí con el celular en la mano, otros se sientan atrás para que así de alguna manera el profesor no les vea fácilmente, por ejemplo en mi salón tengo un compañero que en ninguna clase que no deja de estar con el celular en la mano, ya sea para que jugar o para estar en las redes sociales ${ }^{5}$. Ríen solos, observando aquella pantallita mirando siempre por debajo de la carpeta, creyendo que nadie los verá. Leamos el relato etnográfico de Dina en plena aula de clases:

Un amigo me dice si tenía un cargador porque la batería de su celular se bajó, le dije que no. Ya cuando el profesor empezó con sus clases en el salón lo noté inquieto por no tener el celular en sus manos, ya que este chico la mayoría de clase para con el celular, y al chico del costado le pidió su celular para que le prestara y se puso a estar revisando. Y cuando ya tenía un celular en sus manos se tranquilizó pues ya no volteaba a cada rato ni se movía tanto. ${ }^{6}$

El cuerpo corresponde muy bien al estímulo de los objetos, con particular atención a la tecnología como el caso del celular, lo que nos lleva a tomar en cuenta a los no humanos en la medida en que se vuelven conmensurables con los vínculos sociales (Latour, 2008: 116). Valerio, al igual que muchos otros jóvenes consumidores, con extrañeza nos comenta:

Lo extraño es que con todos los teléfonos que tuve o que tengo (...) siempre pongo en vibrador para todo en llamadas o mensajes hasta con el despertador. No sé pero mis oídos son tan sensibles que puedo escuchar cuando mi celular vibra en la cama, porque lo pongo en despertador y lo pongo bajo mi almohada, a la primera vibrada me levanto, y me ha pasado que saco mi celular pensando que está vibrando y ni siquiera me han llamado. ${ }^{7}$

La paranoia en torno al celular crece a medida que no hay llamadas que recibir o mensajes que responder, peor aun cuando se espera con tantas ansias aquella llamada que nunca llega. Una obsesión que nos desestabiliza, perdiendo la seguridad de nuestras vidas. Este tipo de contingencias nos vuelven cada vez más desconfiados hacia nuestros propios sentidos al punto de preguntarnos ¿Sonó el celular? ¿Vibró? ¿Alguien llamó? Empezaremos a revisarlo una y otra vez, como si rogáramos por alguna nueva llamada.

Dina no esconde sus ansiedades: Sin darme cuenta o para sentir que no pierdo el tiempo, reviso el celular y cualquiera de sus aplicaciones ya sea para ver el calendario y entre otras

Historia de vida de Dina. Julio del 2013

Entrevista a Elvis. Junio del 2013.

Historia de vida a Dina. Julio del 2013

Narración de hechos por Dina.

Entrevista a Valerio. Junio del 2013. 
por simple placer o por esperar con ansias a que entre un mensaje o una llamada ${ }^{8}$. Dicha experiencia pasa por un dinamismo humano-no humano que rebasa la dependencia: vivimos contextos en donde lo tecnológico deja de ser un peligro o una amenaza para convertirse en nuestra más importante extensión y potenciador de nuestros sueños más emotivos. Sara hace un recuento de la molestia que le producen las llamadas impertinentes en la madrugada, a partir de lo cual descubre, con cierta decepción, la vanalidad de aquel artefacto en su vida cotidiana:

Muchas veces me he quejado de lo desconsideradas que son las personas al llamarte o mensajearte en horas de la madrugada. Podría evitar dicho fastidio si simplemente apagara el celular, pero es difícil, piensas que de pronto puedes recibir una llamada importante, urgente y de estar apagado el celular no podrías recibirlo. Ahora que lo pienso, el $99 \%$ de llamadas recibidas de madrugada no eran nada importantes, a pesar de la experiencia sigo durmiendo con el celular cerca. ${ }^{9}$

Para otras personas, aquella relación vital hacia esta tecnología resulta muy perjudicial. Katherine responde así: El poco uso que le doy a mi celular es por una simple razón, cuando lo tengo en uso demasiado tiempo, incluso respondiendo, me da la sensación de que me están controlando; que alguien más sepa que estoy haciendo en todo momento, simplemente me enferma ${ }^{10}$. Sin embargo aquel control se corresponde íntimamente con la noción de ensamblaje. Katherine la rechaza porque identifica en ello una pérdida de su libertad. Su incomodidad hacia esa especie de chantaje entre un sistema social amparado en una tecnología que atraviesa nuestras vidas, la lleva a criticar cuanto le rodea:

Cuando voy par la calle o en el carro me doy cuenta que la mayoría está más pendiente del celular, sea esperando una llamada o la respuesta de un mensaje, viendo eso regresa la sensación de agobio así que simplemente los ignoro lo mejor que puedo. También es molesto cuando las personas te presionan para responder sus mensajes o llamadas como si estuvieras en la obligación de hacerlo. ${ }^{11}$

Aquello que Katherine identifica como obligación, se diluye en las voluntades colectivas, en una relación a la lejanía que nos imposibilita de sentirnos aislados, siempre insertos en aquella realidad virtual, a pesar de nuestro aislamiento. Una obligación que Sara consideró como una tortura en cierta ocasión dado que, debido a un problema en sus labios, no podía hablar. Ella estaba en casa reposando, aislada de su entorno amical ${ }^{12}$ :

Prima de Sara: Qué falta de confianza para no contarme con un mensaje bastaba.

Sara: si, pero no le conté a nadie ah! mi prima me vio yendo al seguro lo divulgo y llovieron las llamadas y la frustración de no poder contestar era unicaaaa!!!!!! pero te conté cuando pude pues!! Encima me cortaron el saldo!!!!! :S hahaha!!! Mas salada!

\footnotetext{
Entrevista a Dina. Julio del 2013

Entrevista sostenida en Junio del 2013.

Entrevista a Katherine. Octubre del 2013.

Ídem.

Diálogo vía chat del Facebook de enero del 2013.
} 
Sin embargo el celular no será siempre una herramienta tan negativa. Nuestra necesidad de ser "controlados" como sostiene Katherine se ve disminuida por la capacidad de poder acercarnos más a quienes, en efecto, se encuentran tan alejados que ni la buena voluntad de verlos nos podría acercar:

Definitivamente mi celular es un medio de comunicación del cual no me despego, ya que de una forma u otra me mantiene cerca y comunicada con las personas que lamentablemente no se encuentran conmigo, el uso que le doy es el adecuado y con buenos fines, sin mi teléfono la atmósfera de mi vida cotidiana sería distinta, ya que necesito sentirme comunicada, porque vivir sola es un nuevo reto y mi celular es un apoyo y una forma de sentir a mis amigos y familiares conmigo. ${ }^{13}$

El caso de Cinthya, que vive en Lima con el fin de estudiar una carrera profesional alejada de su familia localizada en Tacna, nos lleva a pensar un poco más en las perspectivas útiles de las nuevas tecnologías, las cuales alivian nuestras inseguridades y nuestra soledad. Si bien forma parte de nuestros cuerpos a modo de un ensamblaje entre la máquina y lo orgánico, ello no tiene que desembocar en percepciones apocalípticas que destierren la telefonía vía celular, ya que, además de ser imposible, anula la posibilidad de explorar sus bondades en aspectos intersubjetivos.

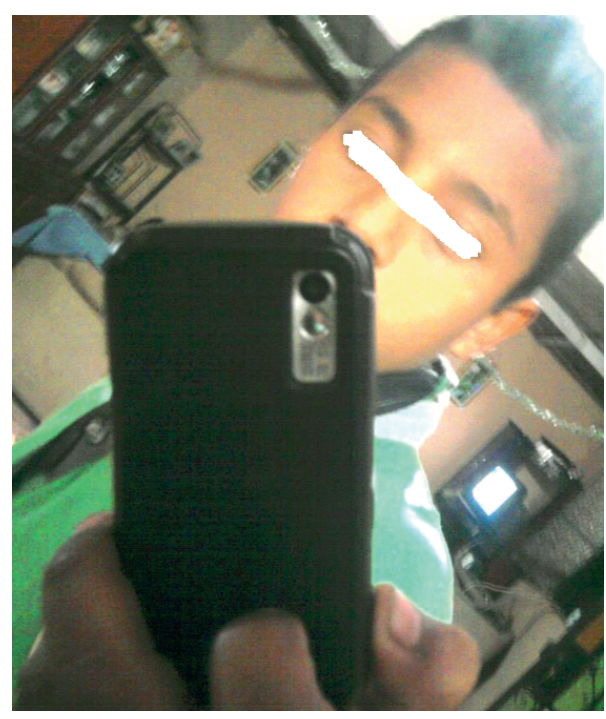

Imagen 1. Las fotografías tomadas por sus propios consumidores nos dejan cierto sabor a que la fotografía no pone en primer plano a su hacedor, sino al celular mismo. Veamos cómo el celular en este caso ocupa no solo gran parte de la fotografía, sino del sentido que el dueño podría depositar en ella. Se trataría de una apología inconsciente al celular. Imagen del Facebook. Setiembre del 2013.

13 Entrevista a Cinthya. Julio del 2013. 


\section{Desbaratando y reacomodando nuestras vidas}

Aquellos artefactos tienen el poder de reacomodar nuestras vidas como nunca antes habría pasado en la cotidianidad menos contingente del pasado. Nuestro futuro sufrirá distorsiones, cambios de último momento, una serie de situaciones inesperadas que nos lleven a reajustar nuestra existencia en un vaivén que las vuelve aún más inesperadas, inclusive en sus aspectos celosamente planificados. Si bien nos ayudan a planificar mejor nuestro cronograma de actividades diarias como es el caso de quien es capaz de ajustar su día según sus objetivos más importantes: A la 5 am le timbro para para despertarlo, entonces me manda un mensaje diciéndome que se va alistar ${ }^{14}$. De este modo los celulares serán capaces de remodelar nuestras citas planificadas con antelación.

Nos avisarán inesperadamente de la cancelación de algún compromiso que, sin la existencia del celular, probablemente, no hubiera sido cancelada. El celular nos permitiría ciertas libertades más allá de las obligaciones. Sabemos que él o ella carga su celular, y al llamarlo podemos arrepentirnos de aquella reunión y decir no. 0 simplemente podemos no responder si estamos decididos a no a efectuar lo que habíamos establecido días antes. Los celulares suenan, nos avisan de alguna nueva situación, nos obligan a salir presurosos al nuevo encuentro. Nos alertan de nuevas o diversas ofertas de reuniones, de exámenes, de trabajos grupales, de fiestas de fin de semana, de algún hombre que decidió invitar al cine a una mujer: son muchas las posibilidades puesto que el celular es una caja de pandora capaz de sorprendernos.

Angélica nos dice: A las 9.10pm recibo una llamada de mi mejor amiga para ver si voy a ir a su casa o no porque ya era tarde, la cual le digo que no podía ir porque se me hizo tarde ${ }^{15}$. A la larga podemos planificar mejor nuestras vidas, del mismo modo que también podemos deshacerla. Veamos el itinerario de Angélica a través de su celular:

2pm: me llama mi mejor amigo para ir almorzar y viajar juntos en la noche a Ica.

7pm: recibo mensaje de mi mejor amigo diciendo que ya estaba en camino y que me alistara.

9pm: me llama mi amigo y me dice que está esperándome afuera de mi cuarto.

10pm: me llama mi papá diciéndome dónde estoy y a qué hora voy a llegar para que me espere, le digo que estaré allá máximo a las 12am o 12.30.

5:20am: me manda un mensaje diciéndome que ya se está saliendo de su casa y va ir a la agencia. Después me llama a las 5.30 de un teléfono público me dice que está en la agencia y yo le digo que ya estoy en camino.

10:30pm: me manda un mensaje diciéndome que ya ha llegado y entonces le respondo le digo que me espere que ya salgo.

El uso del celular no provoca una mayor cancelación de los compromisos que antaño eran confirmadas con antelación: se sostiene, por el contrario, que ahora es posible concertar más citas gracias a que existe la posibilidad de cancelarlas a último momento en caso sea difícil llevarlas a cabo o, acaso, por el simple impulso de hacerlo. Ello conlleva

14 Historia de vida a Angélica. Mayo del 2013. 
a cierta relajación del compromiso volviéndolo líquido e incierto. Esto se encontraría en un contexto social de cierto repliegue económico de los sentimientos, en donde se busca ahorrar, en la medida de lo posible, la fatiga de las emociones y sensaciones que producen las relaciones cara a cara (Loayza, 2016).

Gracias a que se pueden cancelar citas debido a emergencias improbables e inesperadas, nuestro celular nos facilita la vida al ubicar a quien sea a cualquier hora como lo establece un entrevistado anónimo: Lo usé para avisar al médico que cancelaría mi consulta médica, por una práctica en la universidad. A la larga podemos prescindir de todo lo que nos genere dudas, agotando una serie de posibilidades ante la necesidad de buscarnos mejores y mayores oportunidades de lograr nuestros objetivos diarios. Sin embargo, la contingencia que nos acecha desmoronará hasta nuestros más solemnes planes. Con un ejemplo sencillo, Dina lo dice así: Mientras estaba en el micro me puse a jugar juegos en el celular y luego de llamar al rpm (red privada Movistar) de mi amiga, mi hermano me llama y quería su mazamorra y tuve que bajarme antes a comprar y luego otra vez subíal micro y llegar a casa. ${ }^{16}$

Gracias a la movilidad y flexibilidad de esta tecnología en nuestras manos seremos no sólo presas de los designios inesperados que usurpan nuestra tranquilidad. También podemos planificar una noche reservada al estudio: los viernes de círculo en la vida de Santos lo animan y lo llevan a relajarse en la agitada vida universitaria de un estudiante de arquitectura. Analicemos cómo es que Santos va preparando su noche de acuerdo a los mensajes de texto que vienen y van, en un diálogo intenso que los aproxima. Planifican un encuentro cuya copresencia les asegura una noche de diversión:

Mensaje de texto de mi "broder" Manuel: "Gian Carlo porfa ayúdame con la perspectiva won" "hoy nos podemos quedar en mi casa para avanzar los planos"

Respuesta de Jorge7:35 pm - "puta Santos hoy es santo de Nataly además es viernes de círculo!"

Respuesta de la chata 7:36 pm - "hoy es viernes de circulo"

Respuesta de dj mudo 7:36 pm -"ya fue oe wevon vamos a chupar... es cumple de Naty"

Alerta de Nextel, respuesta del pálido 7:36- conversación de 4 minutos sobre el cumpleaños de Nataly y de la reunión amical infaltable que tenemos todos los viernes después de tanto trabajo en el taller.

Respuesta de Jorge 8: 15 pm - "oe bajas ps un ron ya fueron los planos domingo es todo!"

Alerta de nextel del chato 8:45 pm - conversación de 7 minutos sobre el trabajo grupal de asentamientos humanos 1

Mensaje de Natalia 8:25 pm-"Santooosss viernes de círculo :D"

(Mi respuesta a natalia: jaja... hoy es cumple de Nataly:D)

Mensaje de Carlita 9:00 pm-"viernes de circulo!"

(Mi respuesta a Carlita: haha... alcohólica) ${ }^{17}$

16 Historia de vida a Dina. Julio del 2013

17 Autobiografía de Santos. Mayo del 2013. 
Gracias al celular podremos tener un contacto con el resto de amigos y amigas, quienes podrán preocuparse por uno y llamar en caso nos suceda algo, como es el caso de Angélica: A las $7 p m$ recibo la llamada de mi mejor amigo, y me pregunta qué estaba haciendo y como estaba con mi dolor!!!!! Entonces le digo que estoy saliendo con mi sobrinito y mi hermanita a comprar pollo a la brasa para mi familia, ya que mi hermana mayor vino a visitarnos a la casa $^{18}$. De este modo es posible atravesar dificultades, aun en la lejanía o en la soledad puesto que el celular nos acercará a aquellos que yacen a la distancia.

Angélica nos narra: A la 6pm recibo un mensaje de mi amigo para saber cómo estaba de mi salud, ya que tengo una herida interna y gastritis y ese día estaba con dolores. Le respondí que estaba bien solo con un poco de dolor que no podía ser fuerza porque ahí si me dolería más ${ }^{19}$. Aquel artefacto no revertirá la tragedia acaecida, pero la hará menos incierta. Angélica no sólo compartiría su malestar, compartirían con ella los diversos malestares que aquejan a sus amigos: A las 5.20pm me manda un mensaje mi amigo diciéndome que se había golpeado la pierna y que estaba cojo y la conversación fue por lo menos hasta la 6pm. Dina, por su parte, oirá a su amiga, quien necesitará de ella ante dificultades con su pareja: me empezó a contar que se habían peleado con su enamorado y, entre otras cosas, hablamos como una hora y media aproximadamente; felizmente que ambas tenemos rpm, eso ayuda de alguna manera ${ }^{20}$.

\section{Lo tecnológico vuelto orgánico}

El celular además será nuestro aliado en situaciones de extrema importancia. Acaso una muy cotidiana e importante función será la de despertarnos. Dormirá literalmente con nosotros: debajo de nuestra almohada. Ni siquiera la alarma transmitida por especialistas de cuán peligroso puede ser tener un celular cerca a la hora de dormir puede alejar a nuestro más importante cómplice no humano. Angélica nos cuenta: mi alarma de mi celular suena a las 7am me levanto y lo apago pero después suena otra vez mi celular porque está configurada que suene cada 5 minutos después de las $7 a m^{21}$. Si no despertamos al primer anuncio, el celular se "preocupará" en hacerlo constantemente hasta que decidamos levantarnos. No se trata de aquel molesto despertador que era apagado al instante. Nuestro tan preciado celular tendrá la autoridad suficiente de despertarnos con alguna melodía de nuestro gusto. Por si fuera poco, nos tendrá la paciencia suficiente según sostiene Ernesto: mi celular siempre lo utilizo en las mañanas ya que te ayuda bastante como despertador y te da la posibilidad de darte 10 minutos extras para que duermas un poquito más ${ }^{22}$.

Es un efectivo asistente: nos despierta a la hora exacta y lo hace repetidas veces con la paciencia inacabable de un buen compañero multiusos. No solo sirve para comunicarnos, para entablar redes sociales a través del internet, además de la cámara, es capaz de arrancarnos de la cama. Y si no lo hace el despertador, algún otro cómplice en la lejanía lo logrará, tal como lo indica Cinthya: Empieza mi día a las 8:00am, automáticamente tomo mi celular para cancelar mi alarma, perdiendo la noción del tiempo mi celular vuelve a vibrar,

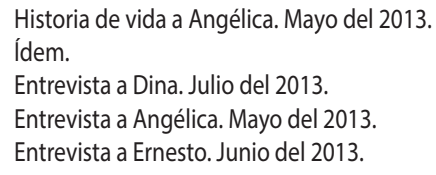


era el Whats App mi amiga me había hablado, para vernos el día domingo en la mañana para un partido de básquet, por ser mi deporte favorito le dije que por supuesto iría $a^{23}$. Además nos avisará cuando algo importante se avecine, tal como Carl lo establece: A las 3:20 p.m. se activó mi alarma para avisarme que ya acabará mi clase ${ }^{24}$. Es así que cada una de sus funciones nos permiten sentirnos plenamente respaldados al final del día: Como estaba cansada todo el día estando en la universidad y clases desde la mañana. No me puse a hablar por celular como lo hago otras veces, solo me puse los audífonos y lo conecté al celular para asi poder escuchar música y entretenerme en algo mientras me quedaba dormida, pero antes de eso puse la alarma en el celular para levantarme temprano ${ }^{25}$. Tiene de todo, música para dormir, un despertador y siempre nos dará la hora.

Continúa Dina su relato en donde da cuenta no sólo de una herramienta, inclusive más allá de su calidad de ensamblado para con nosotros mismos. Pareciera ser un dios del tiempo que administra nuestras vidas, a veces inclementemente, otras de modo muy comprensivo. El celular lo tiene todo lo que necesitamos en el momento indicado:

En la mañana para el día martes 4, empieza a sonar la alarma, me desperté y desactivé la alarma; cuando ya me puse a alistar e ir a la cocina a tomar algo siempre sin separarme del celular, hasta cuando voy al baño a lavarme, mientras me lavo lo pongo en mi bolsillo y estoy pendiente en la hora para controlar y que no se me haga tarde en salir e ir al Instituto. ${ }^{26}$

A todas aquellas facilidades se agregarán algunas dificultades, que en la vida cotidiana pasan tan desapercibidas o acaso son invisibilizadas frente a todo lo positivo que puede ser dicho artefacto hecho uno con nosotros. En este punto me refiero a las ansiedades que van más allá del control que mencionaba Katherine. La telefonía móvil, amparada en el objeto cuya tecnología se hace una en nuestras manos, nos ha traído la costumbre de ver siempre el celular, de modo compulsivo. Como habíamos dicho, al haber crecido y al haberse socializado de la mano con dicha tecnología, las juventudes gozan del celular como quien goza de su brazo derecho para alcanzar algo o del uso de la pierna para patear un balón de fútbol. El celular representa una enorme contradicción de por sí al no estar incorporado al propio cuerpo, al no funcionar de la mano con nuestra anatomía subjetivada, por lo cual provocará continua incertidumbre. Se le necesita coger, agarrar, maniatar, revisar, estar con él y para él porque es mediante el celular que uno se incorpora a las redes sociales juveniles a las cuales se pertenece, mediante él es que nos visibilizamos en sociedad. La ansiedad creada apenas recae en el sujeto desde que empieza el día: coge el celular y con cierta ilusión lo ve ¿tendrá algún mensaje? ¿Alguna llamada perdida?

Sara a diario hará lo mismo, una y otra vez, como quien debe cumplir con un ritual social: Me levanto y reviso si tengo alguna llamada perdida o mensaje texto ${ }^{27}$. Inclusive en las madrugadas, si hay ganas de ir al baño, no dejará de revisar el celular: ya que lo prendo

\footnotetext{
Entrevista a Cinthya. Julio del 2013.

Entrevista a Carl. Julio del 2013.

Entrevista a Dina. Julio del 2013

Ídem.

Entrevista a Sara. Setiembre del 2013.
} 
como linterna para ver, aprovecho y veo si hay mensajes en el WattsApp ${ }^{28}$. Una vez más Dina confesará aquella interpelación al celular en los momentos menos gratos del día: sin darme cuenta o para sentir que no pierdo el tiempo reviso el celular y cualquiera de sus aplicaciones por simple placer o por esperar con ansias a que entre un mensaje o una llamada ${ }^{29}$. La ansiedad por el objeto revela una condición propia de las nuevas tecnologías.

Pero los miedos emergen de aquellos que aún creen lo que los científicos dicen: Ando con el celular siempre en el bolsillo de atrás ya que tengo miedo de las ondas que constantemente entran y salen de los celulares, y creo que en algo me protejo del cáncer de próstata y mi descendenci $a^{30}$. Sin embargo el propio Santos puede neutralizar la intromisión de aquella tecnología que él denomina como cancerígena, o acaso que hace de nuestros cuerpos, víctimas proclives de alguna futura enfermedad: Sali temprano a las 9:00 am con el celular ya que había quedado en comprar los materiales para dirigirme a casa de mi amiga del grupo, pero esta vez el celular lo llevaba en la mochila cosa que mientras lo aleje más de mi cuerpo creo que es mejor para mí, sin embargo tenía que estar atento a cualquier mensaje o llamada del grupo de trabajo ${ }^{31}$. Nadie podrá escapar de las redes virtuales que hacen su aparición mediante múltiples mediadores, todos prestos a inmiscuirse en nuestras vidas, con nuestra venia o sin ella.

A lo ya citado, hay una situación recurrente y preocupante: con la libertad móvil llega también la vigilancia. Hombres y mujeres serán erradicados de su deshonestidad clandestina al momento de tener una pareja sentimental. En buena parte las mujeres serán rastreadas constantemente a diversas horas por enamorados desconfiados y malhumorados que exigen explicaciones, a cualquier hora del día, fortaleciendo aún más los términos patriarcales en los cuales nuestra sociedad no ha dejado de cultivar ${ }^{32}$. Inclusive las mujeres no cesarán de llamar pues los hombres no son dignos de confianza. Hay un término propuesto para esta acción: la "marcación". Si un celular suena y alguien responde con apuro y hasta cierto temor, aquellos que rodean a dicha persona no demorarán en comentar el tipo de "marcación" que sufre aquel o aquella joven. Es un ejercicio de control que deriva en un recorte de la libertad del otro, aunque, a su vez, es legitimada por la mutua vigilancia que puede existir en una pareja.

El celular trae consigo dos elementos dignos de ser subrayados. Por un lado la obsesión de la enamorada o enamorado por saber dónde está la pareja, con quiénes está y que se está haciendo; así mismo trae consigo el miedo y compulsiva necesidad de llamar. La desconfianza brotará si no se responde una vez, empezará a bullir si no responde dos veces y si se prolonga la espera, terminará por exasperar a la pareja inquisitiva, colmando de preguntas posteriores a quien osó no responder. ¿Por qué no respondiste el celular? ¿Dónde estabas? ¿Con quién estabas? ¿Qué estabas haciendo?

De este modo tendremos tanto la limitación de la propia libertad de acción en el mundo afectivo juvenil, así como las inseguridades provocadas por el celular. Nos cuenta Pablo: no habla con su enamorada ni le envía mensajes, tiene problemas con su

28 Ídem.

29 Entrevista a Dina. Julio del 2013.

30 Entrevista a Santos. Mayo del 2013.

31 Ídem.

32 Tal como establece Peinado (2012: 21) el patriarcado se inventó para legitimar una mujer inferior moral, intelectual y físicamente al varón a la que el hombre debía tutelar vigilar y proteger. 
enamorada así que ni le contesta ${ }^{33}$. La sola existencia del celular nos exigirá, de alguna forma, la consecuente necesidad de "marcar" al otro o a la otra, porque, de otro modo, éste puede terminar por cometer alguna infidelidad, o al menos alguna acción fuera del radio acordado de lo permitido por la pareja, como por ejemplo salir a beber, ir a fiestas, salir con amigos o amigas o simplemente hacer algo "incorrecto". Las fantasías colectivas acendradas (Elías, 1989) serán consecuencia, en buena medida, de nuestro cómplice no humano que dinamita las bases de nuestra seguridad.

En esta tónica se me ocurre abordar una última hipótesis. Supuestamente el celular trajo consigo redes cada vez más y más amplias, sin embargo con el celular también aparecería la pérdida de la identidad y de la memoria amical. Me refiero con esto a que los celulares hasta dos o tres años iban y venían, nunca nadie conservaba el número porque este partía con el cambio de equipo celular, salvo algunas personas que lo hacían en su mayoría con cierto tino producto de los contactos laborales.

En su gran mayoría perdían -o acaso los dejaban ir sin mayor preocupación- sus números para siempre. Cambiaban de número y por ende de personalidad volviendo a foja cero. Nuevas amistades renovaban el celular y las viejas desaparecían con la pérdida o cambio del celular anterior. "Lo lamento, perdí mi celular". "Lo siento me robaron". "Oye ya cambié de celular" eran frases comunes en las redes sociales. Pareciera vivenciarse tiempos en que las amistades son formas de vida objeto de sustitución entre sí, actitud reforzada por el uso del celular. ¿Un punto a favor de la modernidad líquida (Bauman, 2007)? ¿Paranoias propias de alguien que puede parecer resistirse a lo inevitable?

\section{Conclusiones}

Apenas se ha mostrado, muy sintéticamente, una mirada descriptiva del suceso que ha representado el celular en estos últimos años. No se ha buscado ser categórico ni profético. Por el contrario se muestra el carácter performativo con el que las tecnologías se incorporan al cuerpo juvenil analizado. Se vislumbra el poder a modo de dispositivo placentero y problemático a su vez. No viene del celular ni de quien lo posee: surge a partir de aquel ensamblaje mutuo. Se abren muchas posibilidades a la vez que se desvanecen otras. El celular y sus múltiples funciones nos llama a ser parte de él y a que sea parte de nosotros.

Esta organicidad que suma a la máquina como parte del cuerpo juvenil impactaría en las vidas de sus usuarios al punto de incrementar el nivel de contingencia en el fluir cotidiano. Los compromisos se deshacen para dar paso a otros nuevos. Es capaz de acercarnos más hacia aquellos con quienes sostenemos vínculos afectivos muy intensos, nos ayuda a enfrentar dilemas cotidianos e insatisfacciones diversas al poder tender puentes con nuestras amistades. Sin embargo nos lleva a desconfiar y a mentir. Recrea una serie de rituales paranoicos con los cuales perseguir a quienes más queremos. Los celos y la desconfían brotan y desestabilizan relaciones amorosas juveniles.

Se vislumbra cómo, a través de estos múltiples ejercicios, el uso del celular nos vuelve dependientes de ciertos usos que antes ni siquiera existían en nuestras vidas. Remodelamos

33 Entrevista a Pablo. Mayo del 2013. 
nuestros días de acuerdo a las nuevas aplicaciones que se nos presentan, subsumiendo nuestras emociones y nuestros cuerpos a la fetichización del mercado.

\section{Bibliografía citada}

Augé, M. (1998). Los no lugares, espacios de anonimato. Barcelona: Gedisa.

Bauman, Z. (2007) Amor líquido. Buenos Aires: Fondo de cultura económica.

Elias, N. (1989). El proceso de la civilización. México D.F: Fondo de Cultura Económica.

Hine, C. (2004). Etnografía virtual. Barcelona: Editorial UOC.

Latour, B. (2008). Reensamblar lo social. Buenos Aires: Manantial.

Loayza, J. (2016). Nuevas corporeidades juveniles en las tecnologías virtuales. En Revista Conjeturas, n. 9, p. 68-99.

Peinado (2012). Reflexiones en torno a la feminidad: claves para entender la pervivencia del patriarcado (1850-1950). En Alberto González Coord. No es país para jóvenes.

Sautu, R.; Boniolo, P.; Dalle P. y Elbert, R. (2005). Manual de metodología. Buenos Aires: CLACSO. 